\title{
CONTEXTO DEPOSICIONAL E EVOLUÇÃO ESTRATIGRÁFICA DE DEPÓSITOS ARENOSOS PLATAFORMAIS A PARTIR DA CARACTERIZAÇÃO SÍSMICA E DE ELETROFÁCIES, MAASTRICHTIANO DA BACIA DO ESPÍRITO SANTO, BRASIL
}

\author{
DEPOSITIONAL CONTEXT AND STRATIGRAPHIC EVOLUTION OF SHELF SAND BODIES \\ FROM SEISMIC AND ELECTROFACIES CHARACTERIZATION, MAASTRICHTIAN INTERVAL \\ OF ESPÍRITO SANTO BASIN, BRAZIL
}

\section{Salomão Alencar Serra NUNES; Jorge de Jesus Picanço de FIGUEIREDO; João Paulo Miranda OLIVEIRA; Fábio André PEROSI; Leonardo BORGHI}

Universidade Federal do Rio de Janeiro. Instituto de Geociências. Avenida Athos da Silveira Ramos, 274 - Cidade Universitária Ilha do Fundão, Rio de Janeiro - RJ. E-mails: salomao@geologia.ufrj.br; j.figueiredo@ geologia.ufrj.br; joao.paulo@geologia.ufrj.br; faperosi@geologia.ufrj.br; lborghi@geologia.ufrj.br

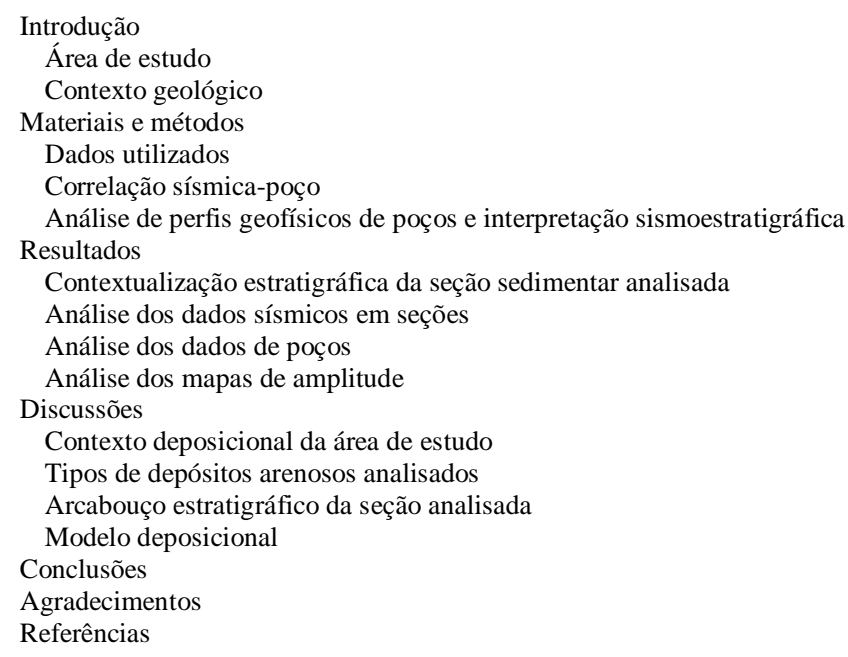

RESUMO - Corpos arenosos de plataforma, como os cordões arenosos (sand ridges), constituem um significativo tipo de reservatório em bacia de margem continental, o que chama atenção para que esses corpos possam ser melhores estudados e caracterizados. Esse trabalho, localizado na região centro-oeste da bacia do Espírito Santo, visa caracterizar esse tipo de depósito, abordando seus atributos geométricos e anatômicos, e interpretar os principais fatores controladores associados à sua origem e evolução, através de uma abordagem baseada nos princípios da estratigrafia de sequências, culminando com a proposição de um modelo deposicional para os mesmos, a partir de dados sísmico 3D, 2D, além de dados de poços, como perfis litológicos, perfis geofísicos e dados cronoestratigráficos. Os sand ridges, do tipo lençol de areia de plataforma, interpretados na área de estudo são caracterizados por refletores positivos de alta amplitude, contínuos, e apresentam uma geometria em lençol. São intercalados por folhelhos caracterizados por refletores negativos de alta amplitude. Por meio dos elementos estratigráficos e deposicionais identificados, assume-se que esses corpos arenosos foram depositados devido a interações entre uma fonte de sedimentos que abastecia a região plataformal, provavelmente, o "paleocânion" de Fazenda Cedro, a dinâmica de avanço e recuo da linha de costa, além de correntes litorâneas e correntes de tempestade, as quais podem ter retrabalhado esses depósitos ao longo da plataforma.

Palavras-chave: Formação Urucutuca; Sand ridges; Interpretação sísmica.

\begin{abstract}
Shelf sand bodies, as the sand ridges, constitute a significant type of reservoir in continental margin basins, which draws attention to a better study and characterization of these bodies. This study, located in the central-western region of the Espírito Santo basin, aims to characterize this kind of deposit and interpret in which stratigraphic and depostional context they might have formed, using 3D, 2D seismic and well data, such as lithologic and geophysics logs, and cronostratigraphic data. The sand ridges, shelf sand sheet type, interpreted in the study area are characterized by high positive amplitude in seismic reflections, continuous, and display a sheet geometry. They are inserted between shales layers characterized by high negative amplitude in seismic reflectors. By means of stratigraphical and depositional elements identified, is assumed those sand bodies were deposited due to interactions between a sediment source that use to supply the shelf region, in this case, the Fazenda Cedro "paleocanyon", and the movement dynamics of the shoreline, besides the coastal currents and wind-driven winter currents, which might have reworked these deposits over the shelf. Keywords: Urucutuca Formation; Sand ridges; Seismic interpretation.
\end{abstract}

\section{INTRODUÇÃO}

Corpos arenosos de ambiente marinho acumulações de areia depositadas entre a linha de plataformal têm sido definidos como costa e a quebra da plataforma (Johnson \& 
Baldwin, 1986). No entanto, existe uma certa contradição terminológica sobre esses corpos arenosos de ambiente marinho raso (Snedden \& Bergman, 1999). Exum \& Harms (1968) referem-se a esses corpos como "corpos marinhos rasos lenticulares"; entretanto, esse termo gerou comparações com cordões arenosos em praias (Johnson \& Baldwin, 1986). Posteriormente, Spearing (1976) definiu esses corpos como "corpos marinhos rasos arenosos de offshore”. Já Tillman et al. (1985); Knight \& McLean (1986) utilizaram o termo "areia (arenito) de plataforma" para descrever depósitos siliciclásticos formados entre a linha de costa e a quebra de plataforma, da mesma forma que na estratigrafia de sequência como definido por Vail (1987).

Também há divergências sobre a interpretação do momento da deposição de corpos arenosos nas plataformas continentais no contexto da Estratigrafia de Sequência. Stride et al. (1982) consideram que a deposição ocorre durante os tratos transgressivos, enquanto que Plint (1988), Posamentier et al. (1993), Berné et al. (1998), H. Zhuo et al. (2014) e X. Zhang et al. (2017) consideram que a deposição se dá durante o trato de mar baixo com posterior retrabalhamento durante o trato transgressivo.

As divergências interpretativas relatadas demonstram uma dificuldade na compreensão da origem de corpos de corpos arenosos de plataforma, sendo que no caso específico da bacia do Espírito Santo, área deste trabalho, inexistem estudos que abordem o termo endereçado nesta pesquisa. Dentro deste contexto, este trabalho visa caracterizar tais corpos abordando seus atributos geométricos e anatômicos, e interpretar os principais fatores controladores associados à sua origem e à evolução através de uma abordagem baseada nos princípios da Estratigrafia de Sequências culminando com a proposição de um modelo deposicional para os mesmos.

\section{Área De Estudo}

O local do estudo situa-se na porção centrooeste da bacia do Espírito Santo, na região marinha plataformal atual, em frente à desembocadura do "paleocânion" de Fazenda Cedro e a sudoeste do complexo vulcânico de Abrolhos, dentro de um volume sísmico com aproximadamente $535 \mathrm{~km}^{2}$ de área, com destaque para a área de interesse na porção nordeste, onde são encontrados os corpos arenosos isolados (Figura 1).

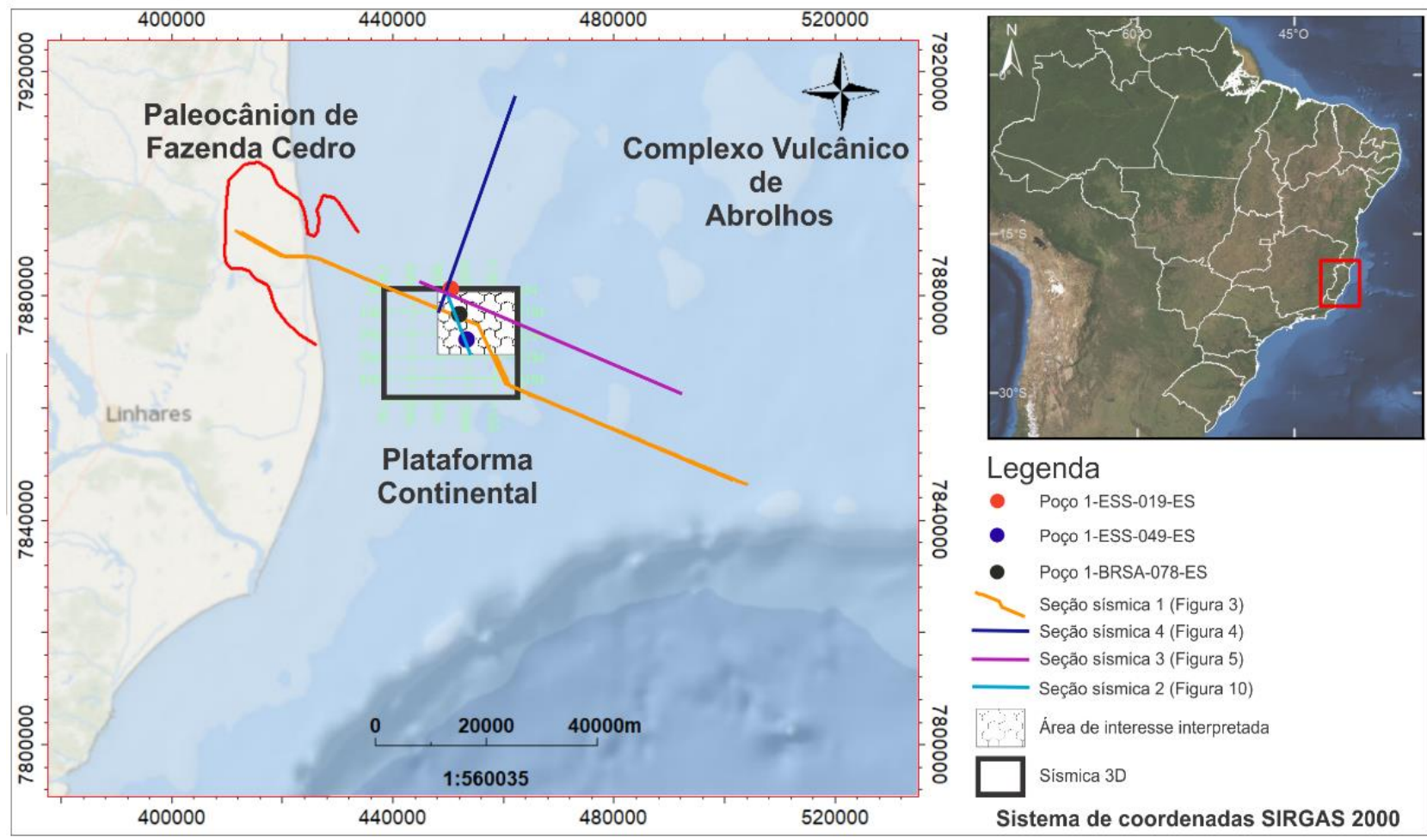

Figura 1 - Mapa de localização da área de estudo com os principais poços utilizados e as seções sísmicas que serão mostradas. Destaque para a área de interesse na porção nordeste, que será apresentada neste trabalho.

\section{Contexto Geológico}

A bacia do Espírito Santo apresenta uma evolução estreitamente relacionada com os eventos associados à divisão do paleocontinente Gondwana, mais especificamente a separação das placas sul-americana e africana (Mohriak, 
2003). Nesse contexto, a bacia do Espírito Santo passou por três principais fases: Rifte, Pós-Rifte e Drifte.

Este estudo concentra-se em uma seção sedimentar específica da fase drifte da bacia do Espírito Santo (Figura 2). França et al. (2007) subdivide a fase drifte em uma seção marinha transgressiva, representada pelo Grupo Barra Nova, e uma seção marinha que reflete um caráter ora transgressivo, ora regressivo, representada pelo Grupo Espírito Santo, depositada entre o Cenomaniano e o Recente.

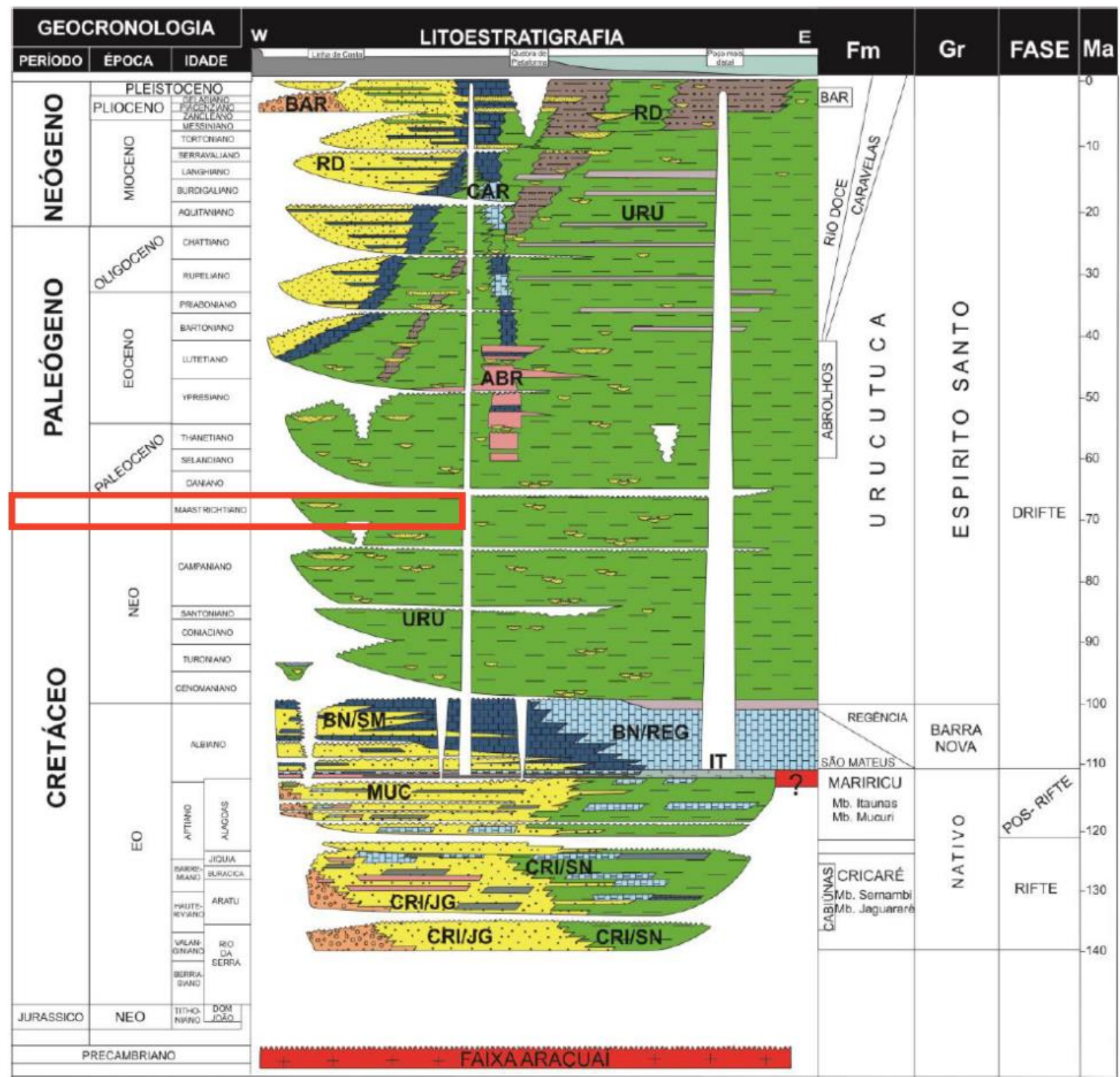

Figura 2 - Diagrama estratigráfico da bacia. A área delimitada pelo retângulo vermelho representa o intervalo de estudo. Fonte: modificado de França et al. (2007).

O Grupo Espírito Santo é composto pelas Formações Urucutuca, unidade litoestratigráfica deste estudo, Caravelas e Rio Doce.

A Formação Urucutuca abrange todo o intervalo associado ao Cretáceo Superior, sendo o intervalo Maastrichtiano de interesse para este estudo (Figura 2). De acordo com França et al. (2007), a seção sedimentar do Cretáceo Superior é limitada na base pela Discordância PréUrucutuca, responsável pela erosão da plataforma carbonática (Formação Regência), a qual se encontra bem preservada na área de estudo, e pela escavação inicial das principais feições erosivas plataformais da bacia, interpretadas na literatura como "paleocânions" (Regência e Fazenda Cedro), e no topo pela Discordância Paleoceno, que marca o limite inferior da seção regressiva. Entre o registro da plataforma carbonática albiana e os arenitos e folhelhos do Maastrichtiano, ocorre o predomínio de folhelhos entre o topo do Albiano e o topo do Campaniano (Figura 2). O limite leste 
do intervalo de estudo, indicado no diagrama estratigráfico da figura 2 tem como referência um

diapiro de sal, o qual também está representado na seção sísmica da figura 3 .

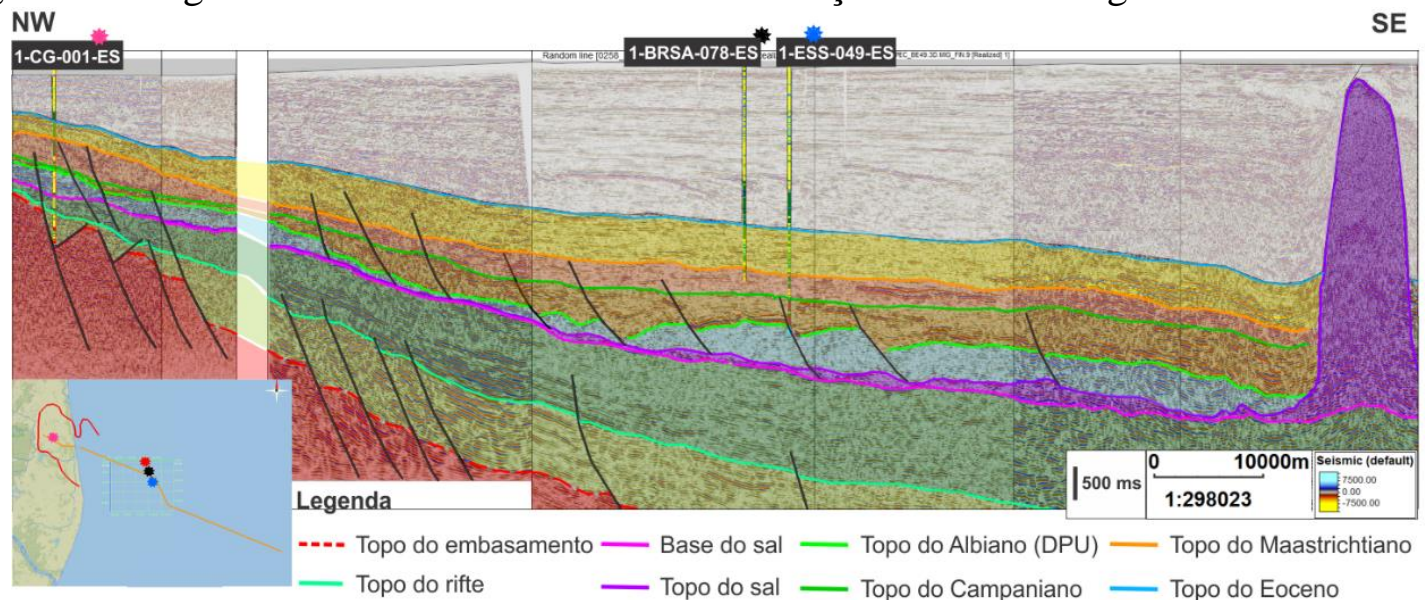

Figura 3 - Seção sísmica composta regional apresentando as principais superfícies regionais mapeadas na região plataformal.

\section{MATERIAIS E MÉTODOS}

\section{Dados Utilizados}

Para realização deste trabalho foi selecionado um volume sísmico, no formato SEG-Y, processado (pos-Stacking), com área de 535,22 $\mathrm{km}^{2}$ (Figura 1). Não foi feito nenhum tipo de processamento nos dados, apenas controle de qualidade antes da interpretação. Com relação aos poços, foram utilizados três poços: 1-ESS-019-ES, 1-ESS-049-ES e 1-BRSA-078-ES, uma vez que apresentam os principais intervalos na área de estudo (Figura 1). Os poços apresentam perfil composto, com descrição cronoestratigráfica. O poço 1-BRSA-078-ES apresenta ainda perfis geofísicos, tais como raios gama (RG), sônico (DT), densidade (RHOB), e porosidade neutrão (NPHI), além checkshot, que consiste em um dado que correlaciona o tempo de trânsito da onda sísmica, em tempo simples (One Way Time OWT), com a profundidade medida (Measure Depth-MD) no poço.

\section{Correlação Sísmica-Poço}

Os dados de poços são amostrados em profundidade, enquanto os dados sísmicos obtidos estão em tempo duplo de trânsito (Two Wat Time TWT), assim, foi necessária a calibração entre as diferentes unidades. A correlação foi realizada com base no sismograma sintético, com o uso do checkshot e dos perfis DT e RHOB. O sismograma sintético é um traço sísmico gerado a partir de dados físicos provenientes das respostas das rochas, que são registrados em perfis geofísicos, como o DT e o RHOB, e no checkshot ou VSP (Veeken, 2007).

O reconhecimento da polaridade dos contrastes de impedância acústicas, entre os topos e as bases dos corpos arenosos, é de vital relevância para a interpretação sísmica. Os perfis sônicos dos poços analisados neste trabalho mostram que os corpos arenosos investigados possuem tempo de trânsito mais baixos que os folhelhos sobre e sotopostos, desta forma, observou-se que estes corpos arenosos possuem velocidades sísmicas mais altas que os folhelhos que os circundam.

A correlação sísmica-poço, permitiu atribuição de idades aproximadas aos horizontes e consequentemente às superfícies de contorno estrutural. Isto foi possível em função dos dados cronoestratigráficos contidos nos perfis compostos dos poços amarrados à sísmica.

\section{Análise de Perfis Geofísicos de Poços e Interpretação Sismoestratigráfica}

Neste estudo, foram reconhecidos cinco horizontes mapeáveis em dados sísmicos, sendo três associados às discordâncias regionais na bacia e dois associados ao topo e à base dos corpos arenosos isolados que foram analisados neste trabalho.

Após o mapeamento dos horizontes foram geradas superfícies, ou seja, mapas de contorno estrutural de cada um deles. As superfícies não foram convertidas de tempo sísmico para profundidade, portanto, as mesmas serão apresentadas em tempo duplo de trânsito (TwoWay-Time - TWT).

Os dados sísmicos permitiram interpretações em escalas variadas de observações. Em uma escala mais ampla, durante análise de sismofácies, as seções sedimentares e os tipos de depósitos são representados de acordo com o caráter sísmico. Também foi possível a proposição de arcabouço 
para a evolução estratigráfica da seção sedimentar do Cretáceo Superior (Mitchum et al., 1977). Em uma escala de maior detalhe foi possível o delineamento da geometria dos horizontes sísmicos interpretados como representantes dos corpos arenosos de plataforma. Nesta escala, também foi possível o delineamento mais claro de superfícies erosivas importantes na construção do modelo deposicional proposto.

Os perfis geofísicos, principalmente raios gama, sônico e densidade, foram importantes para a interpretação de litofácies a partir dos padrões de eletrofácies observadas, como observado por Rider (2000). Após a amarração sísmica-poço, os perfis permitiram uma análise mais detalhada do conteúdo interno do que foi interpretado, como os corpos arenosos de plataforma. Da mesma forma que a sísmica permitiu o delineamento da geometria externa destes corpos, ou seja, sua arquitetura, os perfis geofísicos concederam a observação do caráter interno, ou seja, a composição de tais corpos, resultando na consequente interpretação da distribuição vertical de litofácies.

Para a interpretação da geometria e da distribuição dos corpos arenosos plataformais também foram gerados mapas de amplitudes entre os horizontes do topo e da base dos corpos arenosos. Os métodos utilizados foram: extração da raiz quadrada média de amplitudes ( $R M S$ Amplitude) e soma das amplitudes positivas. Estes atributos sísmicos permitem uma visualização, em mapa, de áreas com forte contraste de impedância acústica. $O$ contraste entre impedâncias acústicas mostradas nos mapas delineia áreas que podem ser interpretadas como diferentes tipos de depósitos, levando-se em conta suas distribuições areais e suas geometrias em planta.

Outros atributos, como o cosine of phase e relative acoustic impedance (RAI), foram utilizados durante a fase de interpretação sísmica. $\mathrm{O}$ cosine of phase melhora a continuidade dos refletores e realça a visualização de quebras e limites, como falhas e limites estratigráficos. Esse atributo é um excelente indicador de continuidade lateral, terminações estratigráficas e variações de fácies sísmicas (Schlumberger, 2011). O RAI mostra o contraste acústico aparente, o que pode indicar limites de sequências, superfícies discordantes e descontinuidades. Ele também pode indicar porosidade ou conteúdo fluido em reservatórios (Schlumberger, 2011).

\section{RESULTADOS}

\section{Contextualização Estratigráfica da Seção Sedimentar Analisada}

A seção sedimentar analisada neste trabalho localiza-se entre os horizontes sísmicos interpretados e denominados como topo do Campaniano e Topo do Maastrichtiano, sendo uma seção correlata às sequências K110 a K130, identificadas por França et al. (2007), que abrangem sedimentos de idade Maastrichtiana. Como é possível visualizar na figura 3 , o intervalo Maastrichtiano não apresenta uma espessura muito grande e é composto por refletores plano paralelos, em sua maioria. $\mathrm{Na}$ figura 3, observa-se também na região dos poços 1-BRSA-078-ES e 1-ESS-049-ES, que a paleoplataforma carbonática (Formação Regência), representada pelo topo do Albiano, se encontra bem preservada e pode ter condicionado as sucessões sedimentares acima dela.

\section{Análise dos Dados Sísmicos em Seções}

A partir do dado sísmico 3D, foi possível identificar que entre os horizontes do topo do Campaniano e do Maastrichtiano ocorre um predomínio de reflexões plano paralelas com forte contraste de impedância acústica. Estes padrões estão localizados na porção norte do volume interpretado. Em seções sísmicas strike, paralelas à paleolinha de costa do tempo Maastrichtiano, portanto, ortogonais ao sentido do paleotransporte sedimentar, observa-se que o referido padrão de reflexão continua, no sentido norte, para além do dado sísmico 3D analisado. Em seções sísmicas 2D, também ortogonais ao sentido do paleotransporte sedimentar, as quais ultrapassam os limites do dado 3D, pode-se mensurar a extensão norte-sul das reflexões plano paralelas com forte contraste de impedância acústica a qual atinge cerca de $35 \mathrm{~km}$ (Figura 4). Em seções sísmicas dip, ortogonais à paleolinha de costa do tempo Maastrichtiano, portanto, paralelas ao sentido do paleotransporte sedimentar, observa-se que as reflexões citadas anteriormente estão praticamente restritas à área do volume sísmico, atingindo cerca de $24 \mathrm{~km}$ na direção leste-oeste (Figura 5). Desta forma, a área de distribuição das anomalias é de cerca de $840 \mathrm{~km}^{2}$.

Os poços 1-ESS-019-ES e 1-BRSA-078-ES, quando amarrados à sísmica, mostraram que a espessura da seção sedimentar relacionada às 


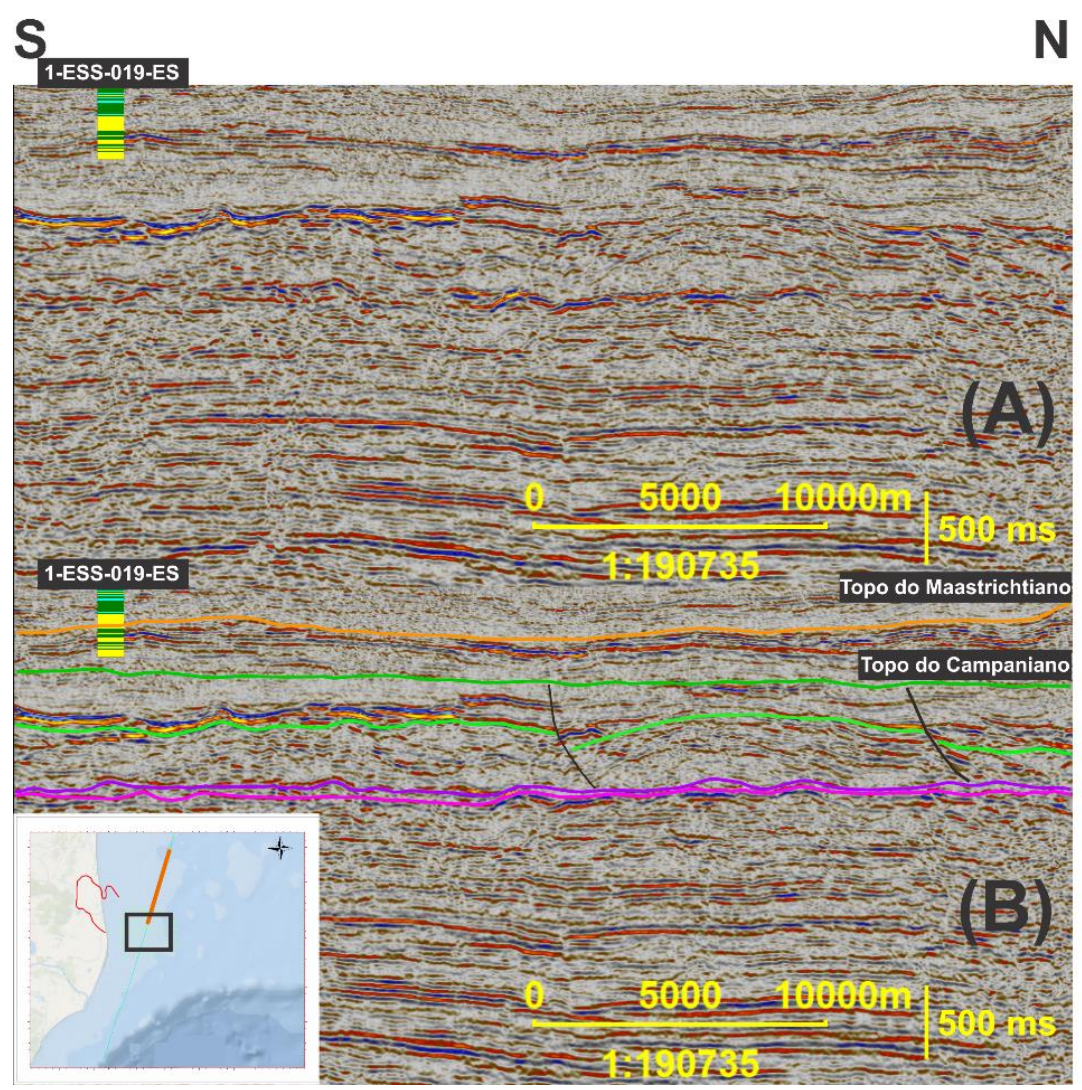

Figura 4 - (a) seção sísmica 2D strike S-N sem interpretação; (b) seção sísmica 2D strike S-N com interpretação Destaque para os horizontes que limitam o intervalo estratigráfico de interpretação, ou seja, o topo do Campaniano (em verde) e do Maastrichtiano (em laranja). Os refletores de alta impedância acústica identificados no intervalo Maastrichtiano apresentam cerca de $35 \mathrm{~km}$ de extensão.

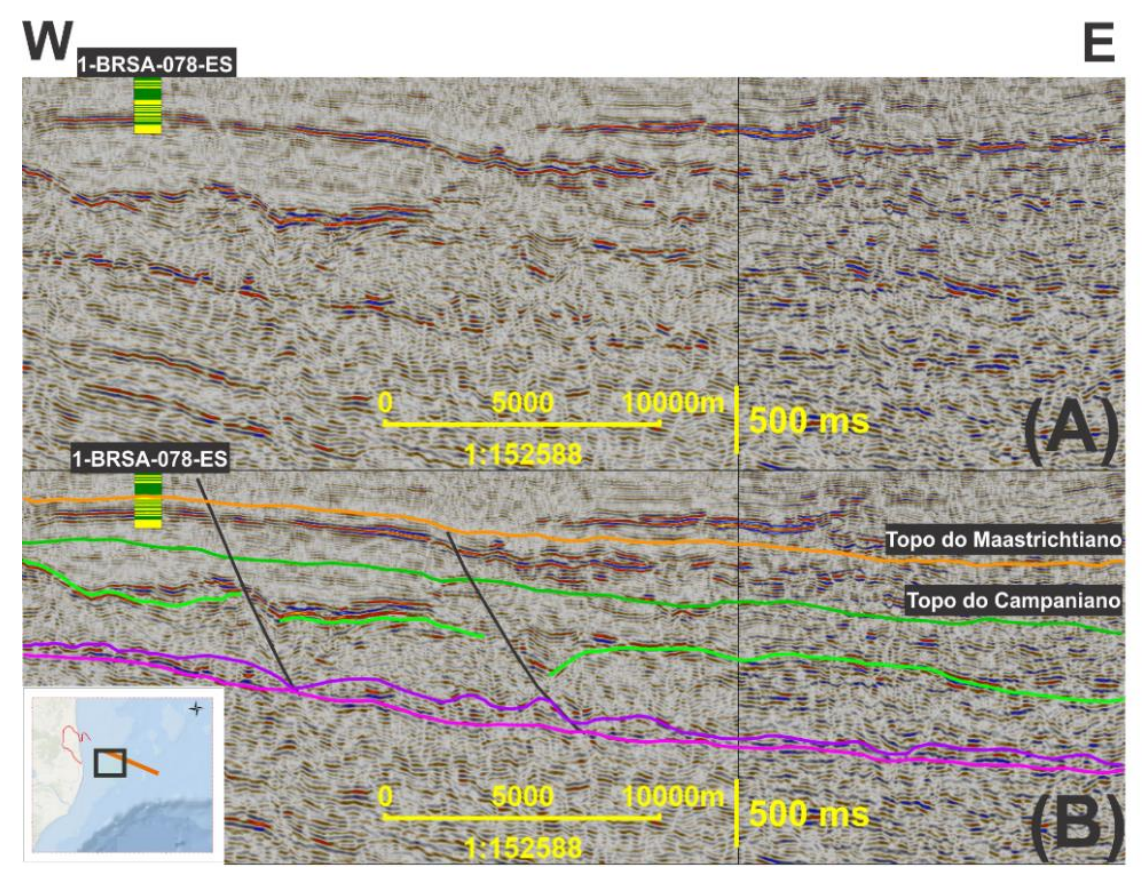

Figura 5 - (a) seção sísmica 2D dip arbitrária W-E sem interpretação; (b) seção sísmica 2D dip arbitrária W-E com interpretação. Destaque para os horizontes que limitam o intervalo estratigráfico de interpretação, ou seja, o topo do Campaniano (em verde) e do Maastrichtiano (em laranja).

reflexões plano paralelas é de aproximadamente 200 m. A espessura em tempo duplo de trânsito (TWT), das reflexões plano paralelas com forte contraste de impedância acústica, é de $100 \mathrm{~ms}$ (milissegundos).
O mapa de contorno estrutural desta superfície (Figura 6) mostra que ela possui um alinhamento com direção próxima a leste-oeste, portanto paralelo ao sentido do paleotransporte sedimentar. 


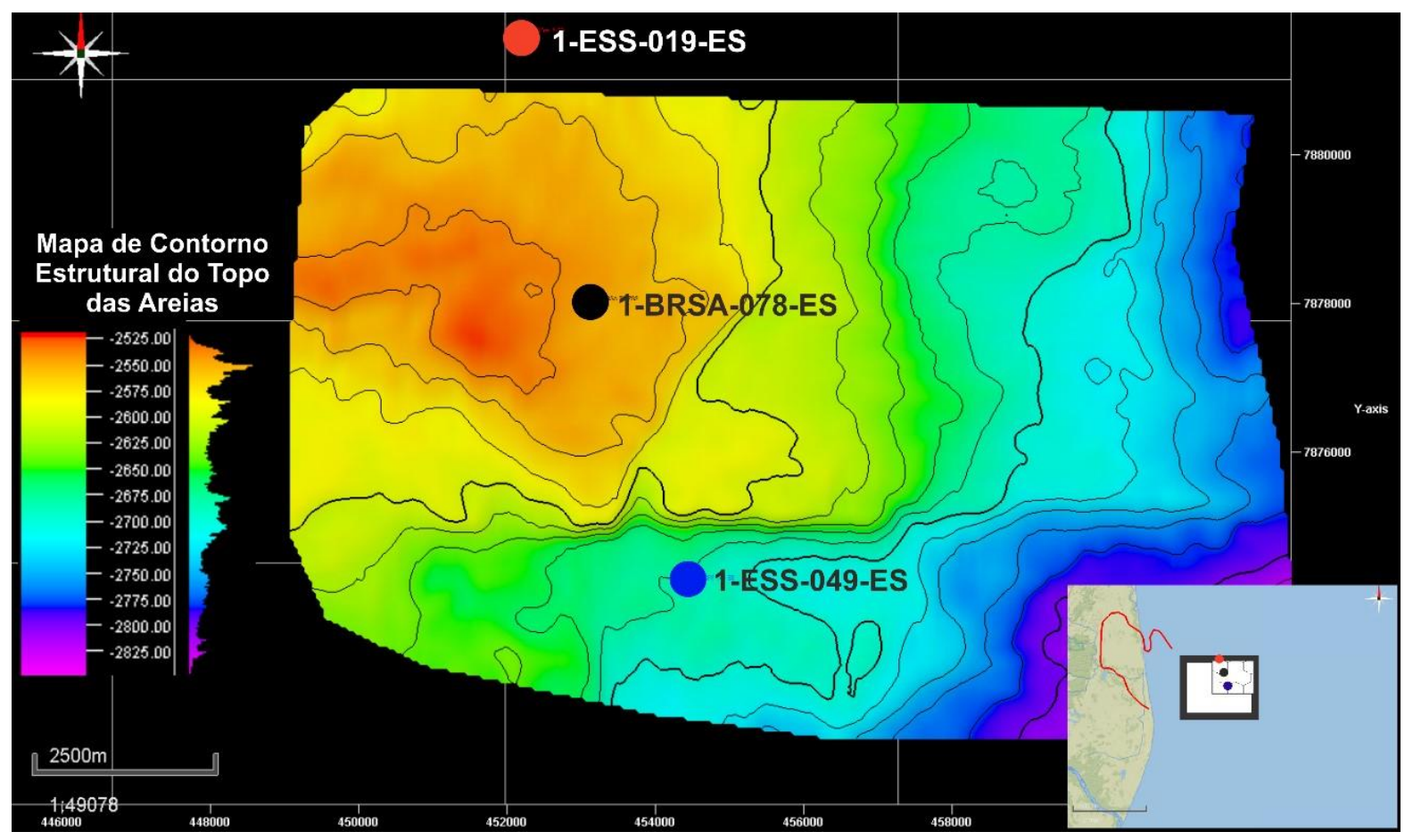

Figura 6 - Mapa de contorno estrutural da superfície do topo dos refletores de alta amplitude. Destaque para a feição erosiva realçada pelo retângulo vermelho tracejado. Em vermelho o poço 1-ESS-019-ES, em preto o poço 1-BRSA-078ES e em azul o poço 1-ESS-049-ES.

\section{Análise dos Dados de Poços}

Após calibração dos poços à sísmica, verificou-se que os dois poços mais a norte (1ESS-019-ES e 1-BRSA-078-ES) atravessaram os refletores de alto contraste de impedância acústica referidos acima, enquanto que o poço mais ao sul (1-ESS-049-ES) está localizado sobre a feição erosiva também reportada acima.

A análise dos perfis geofísicos, principalmente de raios gama, e os dados de descrições litológicas nos poços 1-ESS-019-ES e 1-BRSA-078-ES, distantes entre si em $3,7 \mathrm{~km}$, mostraram que o intervalo correspondente às reflexões plano paralelas é composto por uma intercalação entre depósitos de arenitos e de folhelhos, com predominância dos primeiros. Como folhelhos são, normalmente, depósitos de maior extensão em área, estes são mais apropriados para correlações. $\mathrm{Na}$ seção sedimentar analisada, foram individualizadas e correlacionadas três camadas de folhelhos separando quatro corpos de arenitos (Figura 7).

Por meio da análise das eletrofácies a partir dos perfis de raios gama dos arenitos, baseado em Rider (2000), notou-se um padrão geral em "caixa", no qual não apresenta evidências de tendências de afinamento ou engrossamento do conteúdo granulométrico em direção ao topo ou à base. A curva de raios gama do poço 1-ESS019-ES revelou uma menor variação de leitura nos corpos arenosos se comparado ao poço 1BRSA-078-ES.

Esta variação na leitura desse perfil é denominada por Rider (2000) como "serrilhamento". De acordo com este autor, as eletrofácies dos arenitos podem ser definidas mais especificamente como padrão em "caixa serrilhado" (Figura 7).

O poço 1-ESS-049-ES, mais a sul, localizado nos dados sísmicos sobre a feição erosiva, mostrou um padrão de eletrofácies bem diferente dos dois anteriores nos seguintes aspectos: a espessura da seção arenosa neste poço é inferior à dos dois outros poços; foram individualizados apenas um intervalo arenoso; a análise de eletrofácies deste intervalo evidenciou um padrão em "caixa" sem serrilhamento, gradando para um padrão em "funil serrilhado" na região fora do intervalo entre a o limite de sequência e a superfície erosiva (Figura 7).

\section{Análise dos Mapas de Amplitude}

Foram gerados mapas de amplitude entre os horizontes que delimitam topo e base das reflexões plano paralelas de alta amplitude. Os atributos extraídos foram RMS Amplitude e Soma das Amplitudes Positivas. Como o atributo RMS Amplitude realça todas as anomalias de amplitude, sejam elas positivas ou negativas, optou-se também pela extração do atributo Soma das Amplitudes Positivas, que evidencia os locais 


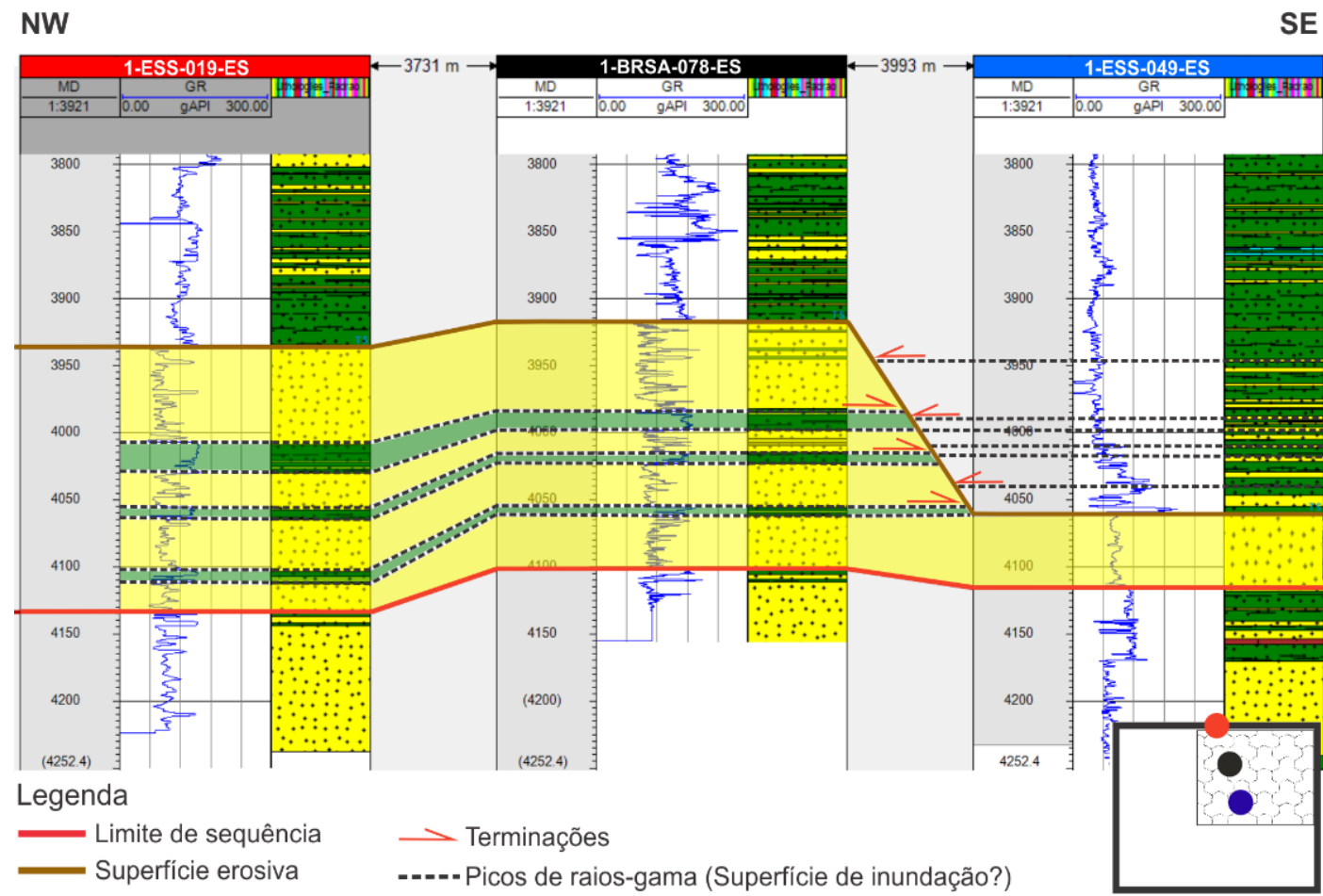

Figura 7 - Correlação entre os poços 1-ESS-019-ES, 1-BRSA-078-ES e 1-ESS-049-ES. Destaque para os níveis de folhelhos correlacionados entre os poços por meio dos picos identificados nos perfis de raios gama, que são truncados por uma superfície erosiva. Uma outra superfície erosiva também é identificada na base dos corpos arenosos de alto contraste de impedância acústica.

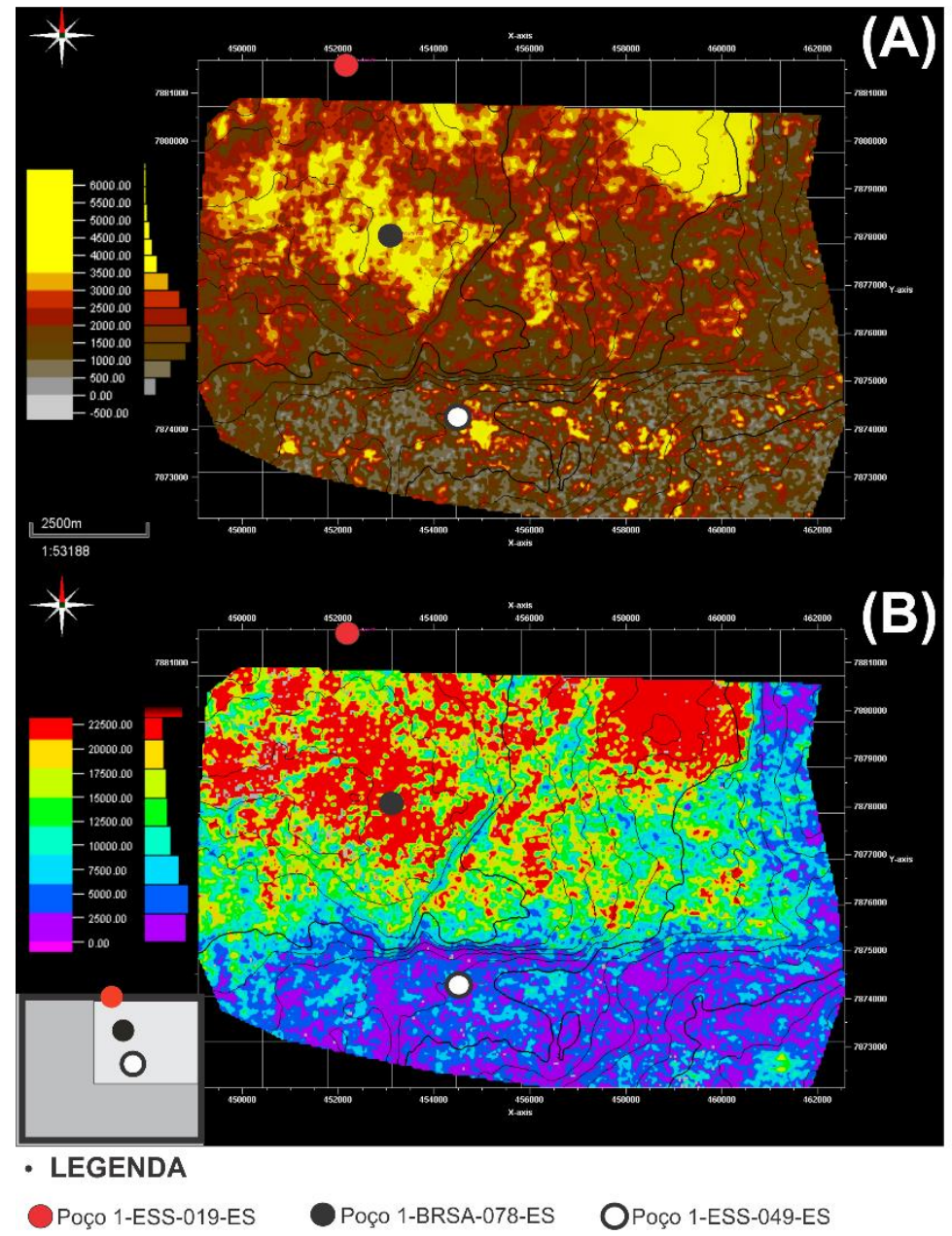

Figura 8 - Mapas de anomalia de amplitude; (a) apresenta o atributo RMS Amplitude e o segundo (b) o atributo soma das amplitudes positivas. Destaque para as anomalias de amplitude localizadas na porção norte da área analisada. 
com predomínio de amplitudes positivas, os quais, como visto anteriormente, representam o coeficiente de refletividade positivo entre os folhelhos sobrepostos aos arenitos na área de estudo. Dessa forma, foi possível verificar que as anomalias de amplitudes identificadas no mapa de $R M S$ são predominantemente positivas, e podem ser associadas a corpos arenosos de plataforma, de acordo com a descrição litológica dos poços. Em mapa, observa-se que as anomalias de amplitude se encontram localizadas na porção norte da área analisada. Apesar da clara variação de intensidade das anomalias de amplitude (Figura 8).

\section{DISCUSSÕES}

\section{Contexto Deposicional da Área de Estudo}

No tempo presente, a área de estudo encontrase na porção mediana da plataforma continental em profundidade de água média de $200 \mathrm{~m}$. Os três poços analisados neste trabalho não contêm informações paleoecológicas sobre o ambiente deposicional da área de estudo durante o Maastrichtiano, porém, a seção sísmica arbitrária dip regional 2D (Figura 3) mostra que a seção sedimentar entre os horizontes sísmicos do topo do Campaniano e topo do Maastrichtiano apresenta pouca variação de espessura considerando-se uma extensão de aproximadamente $100 \mathrm{~km}$. Este padrão de comportamento sedimentar em bacias de margens continentais pode acontecer em dois ambientes deposicionais: bacia profunda, para além do talude continental, e plataforma continental.

A seção sísmica citada acima também mostra que abaixo da área analisada encontra-se bem representada a seção sedimentar correspondente à plataforma carbonática de idade albiana, a qual é dominada por carbonatos de água rasa (Formação Regência). Entre o topo da plataforma carbonática de água rasa do Albiano, representada pela discordância Pré-Urucutuca, e o topo do Campaniano, ocorre uma sucessão sedimentar também com pouca variação de espessura e relativamente delgada para o tempo geológico que ela representa, cerca de 25 milhões de anos. Não há nenhuma evidência morfológica no dado sísmico que sugira que houve um grande aprofundamento da área de estudo após o conhecido contexto de água rasa da plataforma carbonática do Albiano.

Com base na interpretação acima, assume-se neste trabalho que o contexto deposicional da área de estudo durante o Maastrichtiano também era de ambiente plataformal. Ressalta-se que o processo evolutivo da construção do empilhamento sedimentar das seções driftes de bacias de margens continentais começou após a ruptura (break up) continental, com a geometria bacinal mostrando um caráter que se assemelha a uma rampa. A geometria do perfil das bacias da margem continental brasileira só adquiriu a fisionomia clássica de plataforma-talude-bacia no Cenozoico, muito tempo depois da ruptura continental. Desta forma, provavelmente a área de estudo, apesar de estar sendo interpretada como ambiente plataformal, não pode ser comparada com a plataforma rasa e plana do tempo presente da bacia em estudo.

\section{Tipos de Depósitos Arenosos Analisados}

Considerando as características já descritas nas subseções anteriores para as sismofácies, eletrofácies e mapas de amplitude da seção analisada na área de estudo, interpreta-se que as reflexões plano paralelas com forte contraste de impedância acústica representam corpos arenosos não confinados depositados em ambientes plataformais, como discutido no item anterior. Considerando a distribuição areal dos refletores em questão de cerca de $840 \mathrm{~km}^{2}$, como representativa dos depósitos arenosos interpretados, com a dimensão maior paralela à linha de costa, e tendo em vista que a extremidade sul das anomalias se dá por erosão, logo, originalmente, mais extensas, propõe-se que os depósitos arenosos plataformais discutidos estiveram sujeitos a processos relacionados às correntes marinhas de distribuição de areias ao longo da plataforma.

H. Zhuo et al. (2014) descreveram depósitos plataformais com características geométricas semelhantes aos corpos arenosos estudados, como depósitos do tipo lençol de areia de plataforma (shelf sand sheet), do tipo "cordões arenosos plataformais evoluídos", abordagem essa que também foi utilizada nos depósitos arenosos estudados, segundo uma classificação proposta por Snedden \& Dalrymple (1999), que propuseram três estágios evolutivos para "cordões arenosos plataformais" (shelf sand ridges): juvenil, parcialmente evoluído e totalmente evoluído, sendo que os cordões arenosos plataformais mais juvenis se formam sempre próximos à linha de costa. Segundo Goff 
et al. (1999), os "cordões arenosos plataformais" parcialmente e totalmente evoluídos podem também ser tratados, respectivamente, como cordões arenosos de offshore (offshore sand ridge) ou cordões arenosos de plataforma intermediária (mid shelf ridge), segundo Snedden et al. (2011), sendo que, geralmente, a altura, largura e área dos "cordões arenosos plataformais" aumenta com o ganho de profundidade (H. Zhuo et al., 2014).

Esses depósitos com características sismofaciológicas e eletrofaciológicas semelhantes às descritas nos dados analisados neste trabalho (Figura 9) ocorrem na bacia da foz do Rio Pérola, Mar da China Meridional (H. Zhuo et al., 2014). Neste análogo, as ocorrências de areia de plataforma estão distantes cerca de $100 \mathrm{~km}$ em relação à paleolinha de costa, enquanto os corpos arenosos alvos deste estudo estão posicionados cerca de $50 \mathrm{~km}$ plataforma adentro, tomando o "paleocânion" de Fazenda Cedro com referência para linha de costa à época do Maastrichtiano.
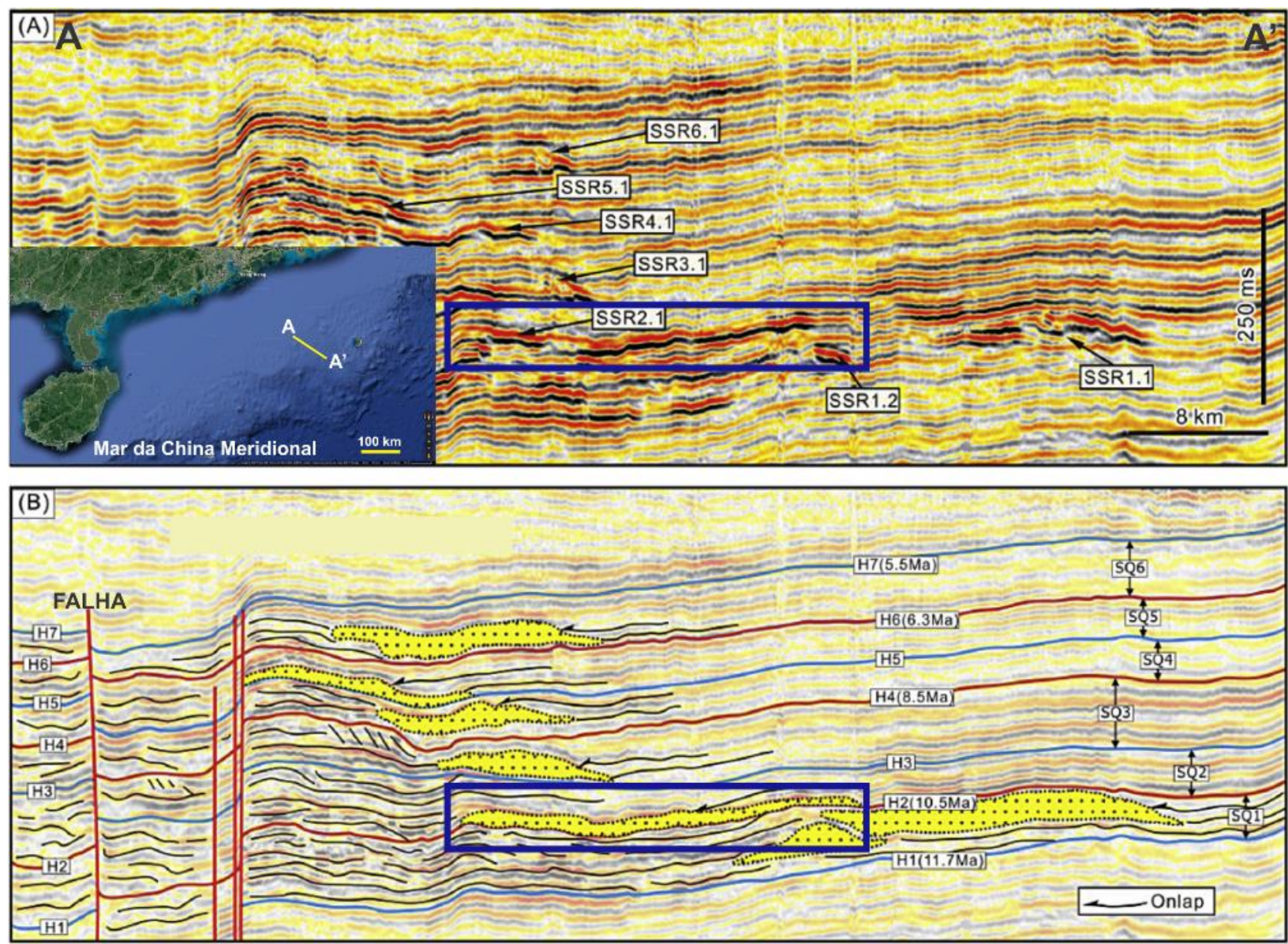

Figura 9 - Seção sísmica mostrando os cordões de areia plataformais do Mioceno da bacia da foz do Rio Pérola, Mar da China Meridional. Esses cordões são caracterizados por refletores de alta amplitude e apresentam uma geometria montiforme (mound), com exceção do cordão SSR2.1, destacada pelo retângulo em azul, que apresenta uma geometria em lençol (sheet). Fonte: modificado de H. Zhuo et al. (2014).

Ao analisar as características desses depósitos da foz do Rio Pérola, é possível inferir que os "serrilhamentos" observados nos perfis de raios gama dos poços estudados podem representar momentos em que a entrada de areia cessou, mesmo que por um pequeno período, seguidos de momentos com uma entrada maior de areia. A mesma observação pode ser feita com os principais níveis de folhelhos que separam os corpos arenosos, onde esses picos maiores nos perfis de raios gama representariam interrupções na deposição de areia, ou seja, estes folhelhos dividem ciclos deposicionais.

\section{Arcabouço Estratigráfico da Seção Analisada}

A seção sísmica (Figura 10) paralela à linha de costa ao tempo da deposição, portanto, ortogonal ao sentido do paleotransporte sedimentar, mostra que os depósitos arenosos representados pelos horizontes sísmicos plano paralelos são limitados por duas superfícies com características erosivas observadas tanto em sísmica quanto em poços. No primeiro caso (Figura 10), notam-se refletores truncados pelas superfícies referidas, e, no segundo caso (Figura 7), nota-se contato litofaciológico abrupto tanto na base quanto no topo do pacote associados aos 
depósitos arenosos. Utilizando as observações feitas nos poços através da variação litológica e dos perfis de raios gama, é possível, inclusive, associar com os padrões de empilhamento característicos do trato de mar baixo e transgressivo, de acordo com o modelo de sucessão de acomodação elaborado por Neal \& Abreu (2009), onde o padrão em "caixa serrilhado" seria associado associado ao padrão de empilhamento progradacional-agradacional típico do trato de sistemas de mar baixo e o padrão de aumento no perfil de raios gama seria associado ao padrão de empilhamento retrogradacional, típico do trato de sistemas transgressivo.

A Superfície basal foi interpretada como um limite de sequência e a superfície erosiva superior como decorrente dos eventos de maior energia relacionados ao pico da taxa de queda relativa do nível do mar, que representa uma descida do nível de base ao tempo chamado de "F-inflection point", que significa a mudança da concavidade da parábola (Figura 11).

No contexto da estratigrafia de sequências, seguindo as proposições de Posamentier et al. (1988) e Posamentier \& Vail (1988), os pacotes de arenitos interpretados teriam sido depositados durante os estágios iniciais do trato de sistemas de mar baixo, em uma sequência deposicional de baixa frequência (baixa ordem).

Os espessos folhelhos sobrepostos ao pacote de arenitos, acima do intervalo de estudo, são interpretados como os depósitos transgressivos desta sequência de baixa ordem.

Assim, infere-se uma ausência de registro geológico entre o topo dos arenitos e a base dos folhelhos referente ao tempo restante do trato de mar baixo após o "F-inflection point".

Para este tempo, interpreta-se que a área onde localizam-se os depósitos arenosos analisados atuou como uma zona de passagem de sedimentos (by-pass) para regiões mais distais da bacia (Figura 11).

O conjunto de depósitos arenosos foi subdividido em quatro corpos separados por delgados folhelhos correlacionáveis nos poços e mapeáveis em sísmica.

Estes corpos individualizados são aqui interpretados como relativos ao trato de sistema de mar baixo de sequências deposicionais de mais altas frequências (altas ordens), interpostas à sequência de baixa ordem citada acima.

Por sua vez, os folhelhos que separaram os arenitos são interpretados como depósitos do trato de sistema transgressivo das sequências de alta frequência (Figura 11).

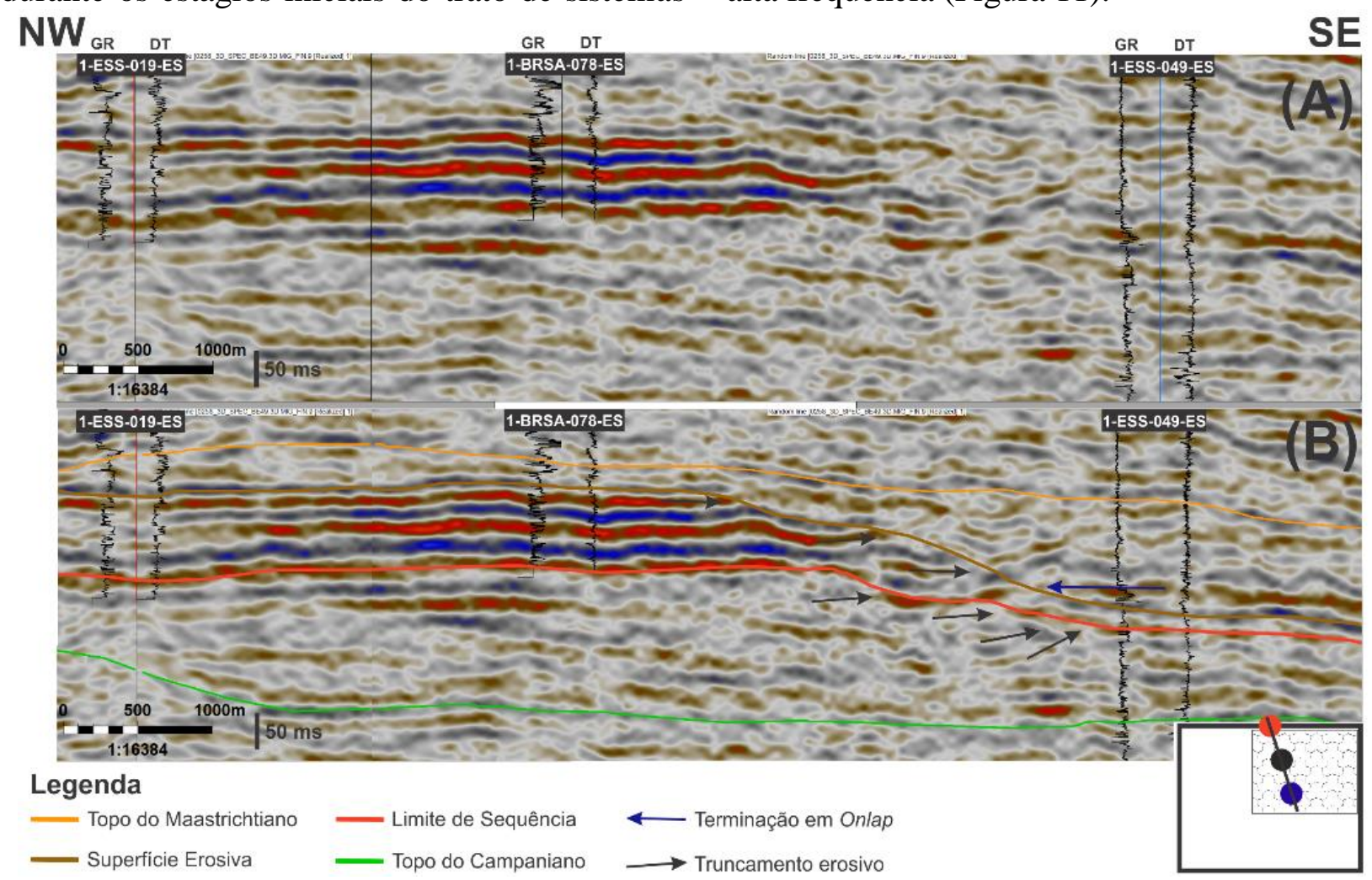

Figura 10 - (a) seção sísmica transversal arbitrária NW-SE sem interpretação; (b) seção sísmica transversal com interpretação mostrando o intervalo estratigráfico entre os horizontes interpretados como os topos do Campaniano e do Maastrichtiano. Contido nesta seção sedimentar, aparece o intervalo de estudo neste trabalho, representado por refletores com alto contraste de impedância acústica. 


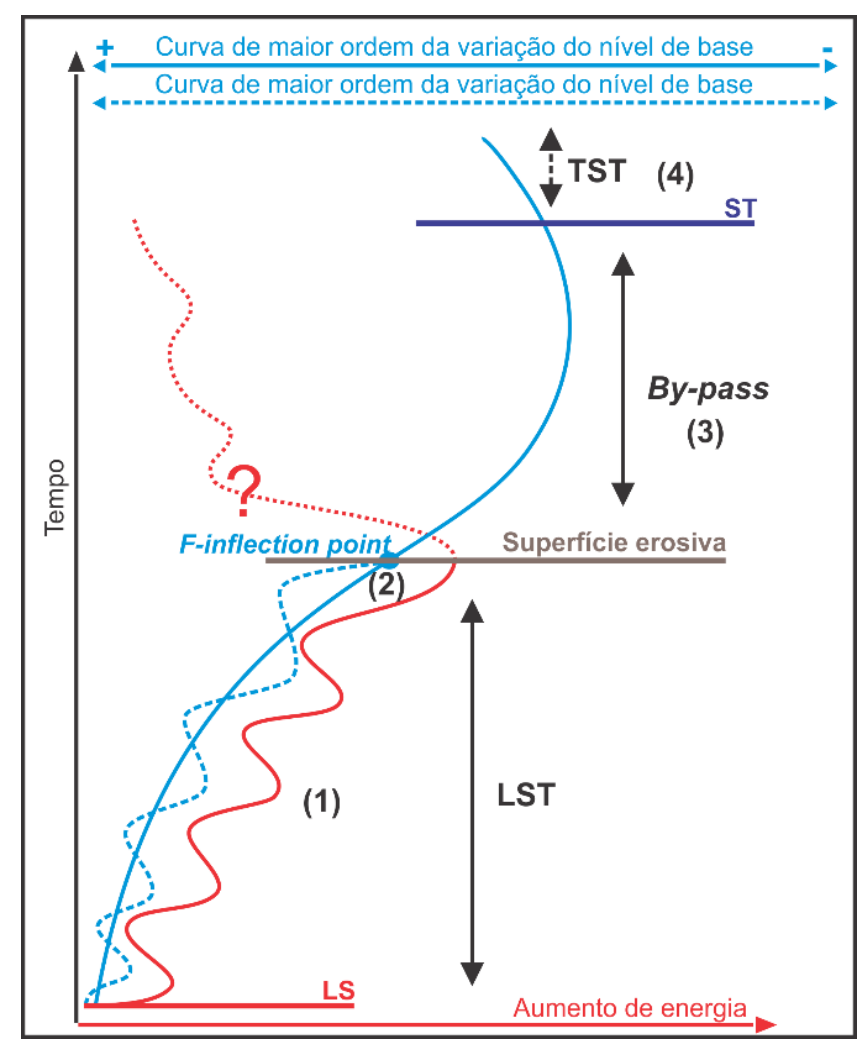

Figura 11 - Curva representando a variação do nível de base no tempo (em azul) e curva representando a variação de energia no tempo (em vermelho). 1 - Variações de alta frequência do nível de base; 2 - " $F$-inflection point", e, 3 - período com predomínio de passagem de sedimentos (by-pass) e 4 - trato transgressivo que se instalou sobre a superfície erosiva.

Em um contexto mais abrangente, os corpos arenosos analisados neste trabalho fazem parte de uma sequência deposicional interpretada por França et al. (2007) como de segunda ordem, compreendendo um tempo de aproximadamente dez milhões de anos. Na figura 10, é possível observar que os horizontes sísmicos interpretados como corpos arenosos constituem, em termos de espessura, cerca de um terço do que seria a sequência de segunda ordem de França et al. (2007). De forma tão somente comparativa, especula-se que a sequência de baixa ordem interpretada neste trabalho poderia ser uma sequência de terceira ordem, enquanto as sequências de mais alta frequência poderiam ser de quarta ordem.

\section{Modelo Deposicional}

O modelo conceitual proposto para a evolução deposicional da seção sedimentar estudada foi baseado em Plint (1988) e H. Zhuo (2014), os quais propuseram que corpos arenosos plataformais ortogonais ao sentido do paleotransporte sedimentar e alinhados paralelamente à linha de costa podem ser depositados durante os estágios iniciais dos tratos de mar baixo de sequências deposicionais. De acordo com H. Zhuo (2014), estes corpos podem ser classificados como cordões arenosos plataformais, possuindo características de depósitos do tipo lençóis de areias de plataforma (shelf sand sheet).

Como proposto no modelo idealizado na figura $13 \mathrm{~A}$, com o deslocamento da linha de costa em direção à bacia, os depósitos arenosos mais proximais tendem a acompanhar essa movimentação, se espalhando ao longo da plataforma e formando corpos tabulares e não muito espessos, devido ao reduzido espaço de acomodação.

Como mostrado no modelo elaborado por Plint et al. (1988), a taxa de queda do nível relativo do mar excede a taxa de subsidência, até o momento em que a acomodação se torna nula e os depósitos plataformais fiquem emersos (Figura $12 \mathrm{~B}$ ).

Nesta situação, a tendência é que tais depósitos sejam degradados por eventos erosivos, porém, Plint et al. (1988) assinalam que devido às variações relativas do nível do mar de alta frequência superimpostas à lenta, mas constante, subsidência da bacia, os depósitos arenosos plataformais são preservados sotopostos a depósitos oriundos do trato transgressivo de alta frequência representados por delgadas camadas de folhelhos (Figura 12 D). 
De acordo com (Huthnance, 1982), os fatores importantes para a formação de cordões arenosos plataformais longitudinais à linha de costa são: o suprimento sedimentar suficiente e correntes que redistribuam as areias na plataforma. Dessa forma, o "paleocânion" de Fazenda Cedro, localizado a montante em relação aos corpos arenosos analisados neste trabalho (Figura 1), pode ter contribuído como fonte alimentadora das areias necessárias para a construção dos cordões arenosos plataformais do tipo lençol de areia de plataforma.

O modelo de Plint et al. (1988) corrobora a interpretação proposta neste trabalho, pois, como pode ser visto na correlação dos poços (Figura 7), camadas de areias bem definidas, interpretadas como cordões arenosos, são separadas por camadas de folhelhos, representantes dos tratos transgressivos das sequências de alta frequência. Também pode ser observado que tanto na base quanto topo dos corpos arenosos ocorrem contatos abruptos.

Os contatos basais abruptos ocorrem em função de deposição de areias de um trato de mar baixo sobre folhelhos de um trato transgressivo, já o contato superior abrupto é interpretado como decorrente de uma combinação da ação de vários processos: (1) retrabalhamento do topo das camadas pelas correntes que eventualmente redistribuíram as areias na plataforma durante a fase de deposição das mesmas; (2) processos erosivos relacionados ao tempo em que os depósitos permaneceram emersos; (3) erosão devido à ação da superfície transgressiva no período de colmatação dos cordões arenosos. A combinação destes diferentes tipos de degradações sofridas pelos cordões arenosos plataformais podem ter segmentado eles, separando-os em corpos isolados ou, pelo menos, diminuído suas espessuras localmente.

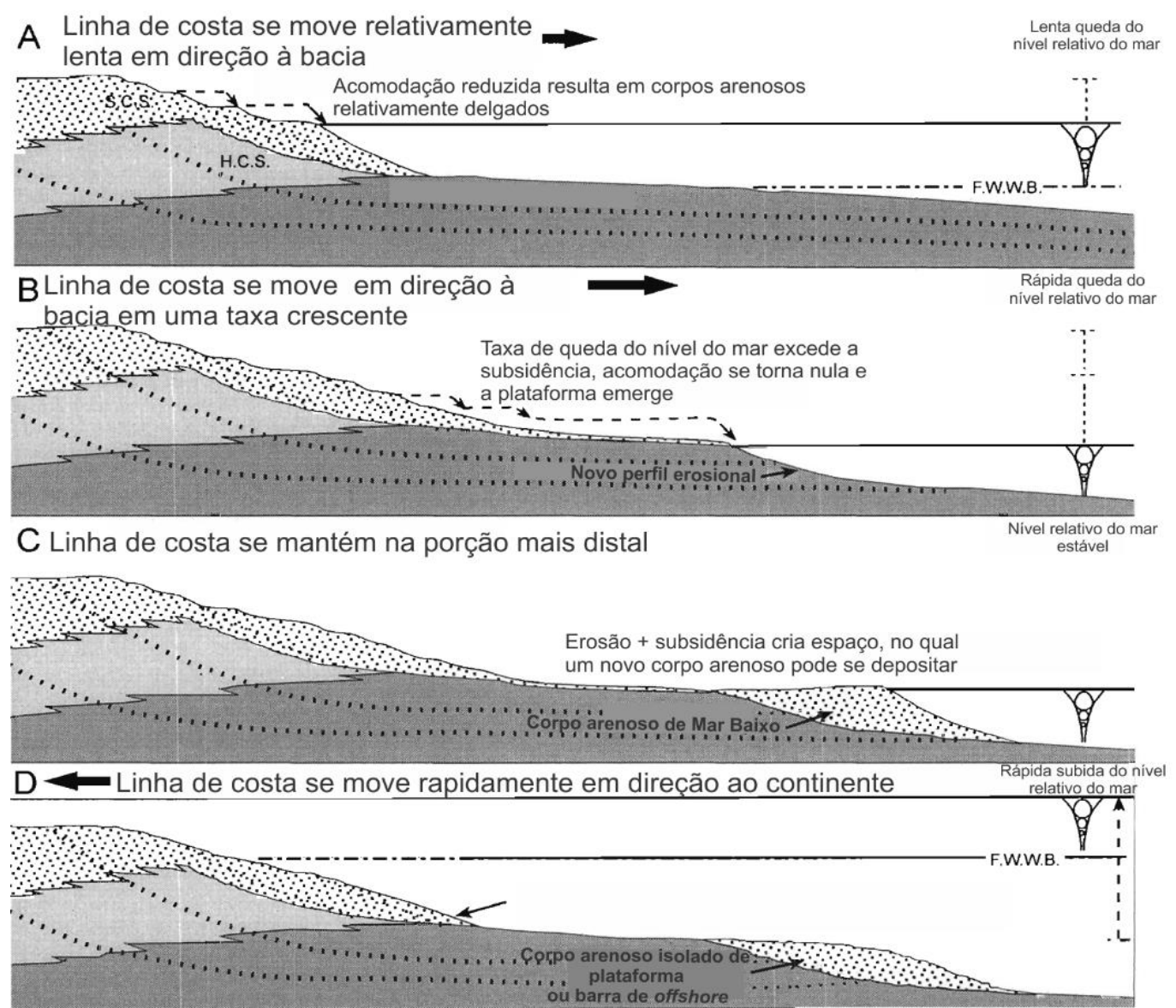

Figura 12 - Modelo para a deposição e preservação de corpos arenosos marinhos rasos devido a uma combinação de variações relativas do nível do mar e de subsidência bacinal. Fonte: modificado de Plint et al. (1988).

Esta possibilidade pode ter condicionado a resposta observada nos mapas de amplitudes sísmicas, os quais mostram áreas com fortes amplitudes, as quais representariam depósitos arenosos espessos, logo, pouco degradados, e áreas de baixas amplitudes, as quais representariam o seccionamento ou a degradação dos cordões arenosos por processos erosivos (Figura 8).

Como discutido no item da evolução 
estratigráfica, os cordões arenosos empilhados durante os estágios iniciais do trato de mar baixo de uma sequência deposicional de alta frequência foram limitadas no topo por uma superfície erosiva bastante proeminente e claramente observada em dados sísmicos (Figura 10).

Essa superfície seria o resultado dos eventos erosivos de maior energia, durante o trato de mar baixo, os quais ocorrem ao tempo do $F$-inflection point mostrado na figura 11 .

Tal superfície erosiva, representada no modelo deposicional proposta na figura $13 \mathrm{c}$, em uma seção transversal (NW-SE) ao paleotransporte de sedimentos, é o registro, na área estudada, de uma fase de passagem de sedimentos arenosos para águas mais profundas (by-pass). Também é possível inferir, dado ao posicionamento das porções mais incisivas da superfície erosiva, geograficamente localizada à frente do "paleocânion" de Fazenda Cedro (Figura 1), que a mesma estaria ligada a um sistema alimentador de sedimentos geneticamente relacionado ao "paleocânion".

Nos poços analisados, foram observados que sobre o topo da camada mais superior dos arenitos, topo este que representa a superfície erosiva discutida acima, aparece uma espessa seção sedimentar dominada por folhelhos. Estes folhelhos são interpretados como depósitos do trato de sistema transgressivo da sequência deposicional de baixa frequência.

Assim, é possível inferir um hiato entre o topo das areias e a base dos folhelhos correspondente ao tempo da variação do nível de base da bacia entre o F-inflection point e algum momento dentro do trato transgressivo.

(A) Trato de sistema de mar

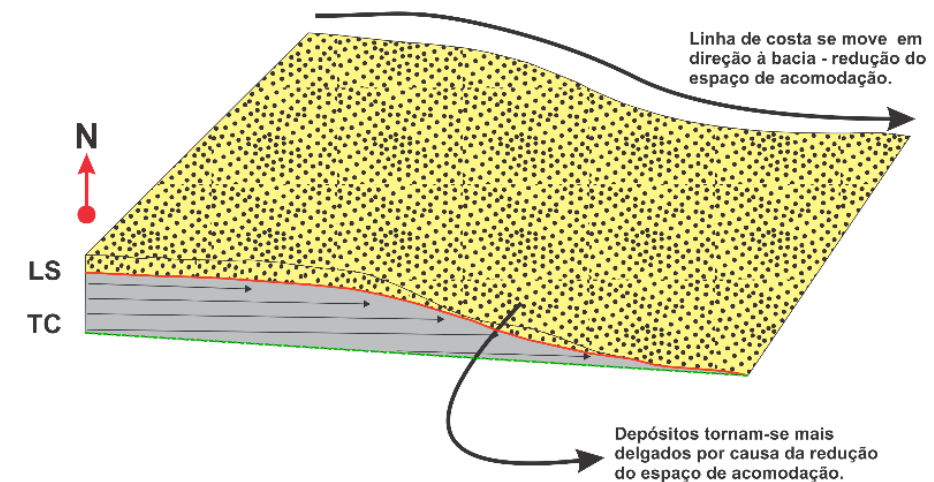

(B) Trato de sistema transgressivo.

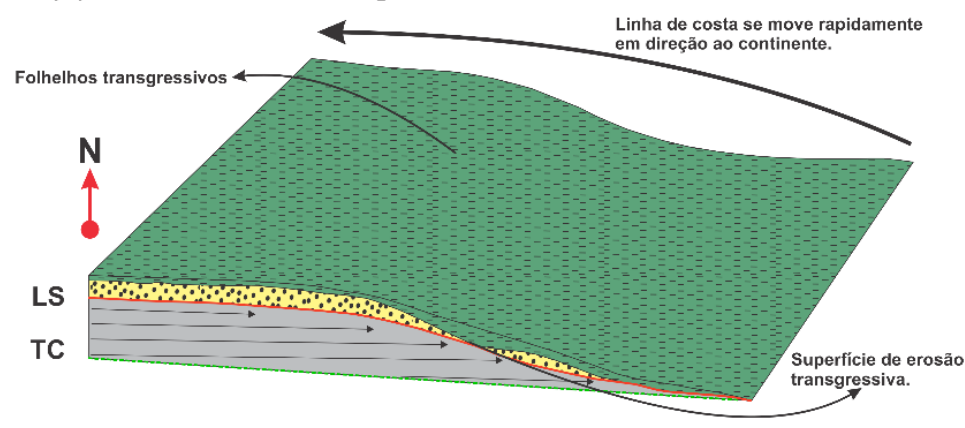

(c) Degradação (By-pass).

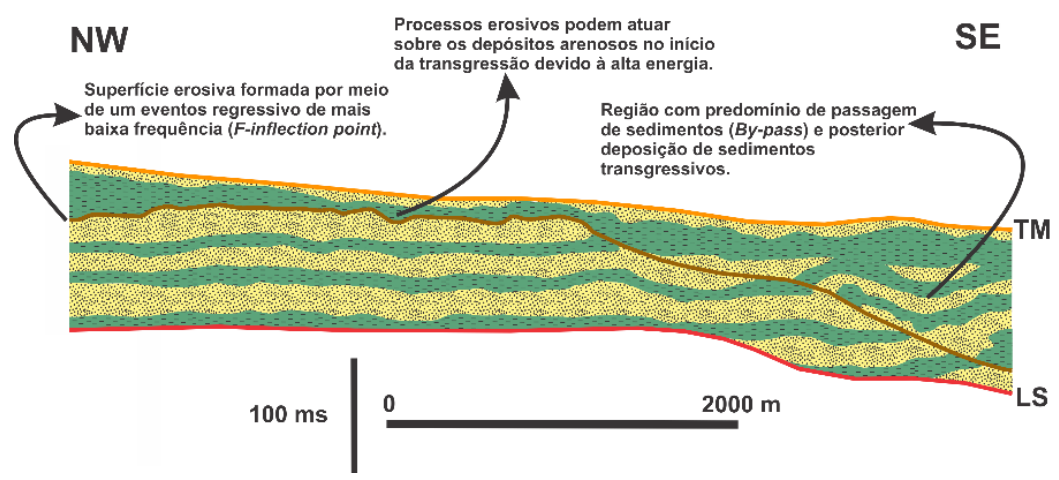

Figura 13 - Modelo deposicional proposto para os depósitos estudados. a) depósitos arenosos sobre o limite de sequência no contexto deposicional de trato de mar baixo; b) contexto deposicional transgressivo, no qual ocorre erosão nos momentos iniciais e deposição de folhelhos em seguida; c) seção esquemática com foco na instalação da superfície erosiva (degradação) que atuou sobre os cordões arenosos plataformais. 


\section{CONCLUSÕES}

Para o intervalo do Maastrichtiano estudado, foram identificados quatro corpos arenosos plataformais, que foram interpretados como cordões arenosos plataformais, utilizando um conjunto de dados sísmico 3D, 2D e de poços, de acordo com as constatações abaixo:

(1) Por meio das seções sísmicas 2D, foi possível estimar que os cordões arenosos são mais alongados no eixo N-S, paralelas à paleolinha de costa.

(2) Foi possível verificar uma mudança no padrão de amplitude dos refletores na porção sul e leste no mapa de amplitude apresentado, que foi condicionada pela ação de uma superfície erosiva em um sentido W-E e possivelmente pela atuação de paleocorrentes de direção N-S, respectivamente.

(3) Por meio das superfícies estratigráficas interpretadas e dos padrões de empilhamento identificados tanto na sísmica quanto nos poços, foi possível inferir que os depósitos plataformais estudados são classificados como cordões arenosos plataformais depositados em um contexto de trato de mar baixo, o que também foi verificado em análogos apresentados neste trabalho.

O modelo deposicional conceitual, elaborado a partir do arcabouço estratigráfica da seção de estudo, procurou mostrar a dinâmica durante a formação dos cordões arenosos plataformais, que foram associados a ciclos de alta frequência da subida e descida do nível de base.

\section{AGRADECIMENTOS}

Agradeço o Laboratório de Geologia Sedimentar da Universidade Federal do Rio de Janeiro (LAGESED-UFRJ) por toda a infraestrutura e capacitação que recebi, principalmente por todo o suporte que tive dentro do Projeto Delta II. Também agradeço aos Professores Jorge Figueiredo, Fábio Perosi e Leonardo Borghi pelas orientações durante o mestrado, além do coordenador técnico do Projeto Delta II e também coorientador João Paulo Oliveira. Além disso, gostaria de agradecer as empresas ONGC e Schlumberger pelo apoio financeiro e disponibilidade dos softwares utilizados neste trabalho, respectivamente.

\section{REFERÊNCIAS}

BERNÉ, S; LERICOLAIS, G; MARSSET, T; BOURILLET, J. F.; DE BATIST, M. Erosional offshore sand ridges and lowstand shorefaces: exemples from tide- and wave- dominated environments of France. J. Sediment. Res, v. 68, n. 1, p. 540$555,1998$.

EXUM, F.A. \& HARMS, J.C. Stratigraphic traps, Western Nebraska. Association of Petroleum Geologists Bulletin, v. 52, n. 1, p. 1851-1869, 1968.

FRANÇA, R.J.; REY, A.C.D.; TAGLIARI, C.V.; BRANDÃO, J.R.; FONDANELLI, P. Bacia do Espírito Santo. Boletim de Geociências da Petrobrás, v. 15, n. 2, p. 501-509, 2007.

GOFF, J.A; SWIFT, D.J.P; DUNCAN, C.S; MAYER, L.A.; HUGHES-CLARKE, J. High-resolution swath sonar investigation of sand ridge, dune and ribbon morphology in the offshore environment of the New Jersey margin. Marine and Petroleum Geology, v. 161, p. 307-337, 1999.

HUTHNANCE, J.M. Ono ne mechanism forming linear sand banks. Estuarine and Coastal Marine Science, v. 14, p. 79-99, 1982.

JOHNSON, H.D. \& BALDWIN, C.T. Sedimentary Environments and Facies. Blackwell Scientific Publications, p. 229-283, 1986.

KNIGHT, R. J. \& MCLEAN, J. R. Sands and Sandstones. Calgary. Canadian Society of Petroleum Geologists Memoir, v. 11, 580 p., 1986.

MITCHUM, R.M.; VAIL. P.R.; SANGREE, J.B. Seismic stratigraphy and global changes of sea level, Part 6: Stratigraphy interpretation of seismic reflection patterns in depositional sequences. In: PAYTON, C.E. (ed.). Seismic Stratigraphy- Applications to Hydrocarbon Exploration. Tulsa: American Association of Petroleum Geologists, v. 26, p. 117-133, 1977.

MOHRIAK, W.U. Bacias sedimentares da margem continental brasileira. In: BIZZI, L.A; SCHOBBENHAUS, C; VIDOTTI, RM. \& GONÇALVES, J.H. (eds.). Geologia, tectônica e recursos minerais do Brasil. CPRM, p. 87-165, 2003.

NEAL, J. \& ABREU, V. Sequence stratigraphy hierarchy and the accomodation succession method. Geology, v. 37, p. 779-782, 2009.

PLINT, A.G. Sharp-based shoreface sequences and "offshore bars" in the Cardium Formation of Alberta: their relationship to relative changes in sea level. In: WILGUS, B. S; HASTINGS, C.G.ST.C; KENDALL, H.W; POSAMENTIER, C.A; ROSS, J.C.; VAN WAGONER (Eds.). Sea Level Changes: An Integrated Approach. SEPM, Special Publication, p. 357-370, 1988

POSAMENTIER, H.W; SUMMERHAYES, C.P; HAQ, B.U.; ALLEN, G.P. Sequence stratigraphy and facies associations. Oxford: International association of sedimentologists special publication v. 18, 350 p., 1993.

POSAMENTIER. H. W. \& VAIL. P. R. Eustatic controls on clastic deposition II - Sequence and systems tract models. In: WILGUS, B. S; HASTINGS, C. G. ST. C; KENDALL, H. W; POSAMENTIER, C. A; ROSS, J. C. \& VAN WAGONER (eds.). Sea Level Changes: An Integrated Approach. SEPM, Special Publication, p. 125-154, 1988.

POSAMENTIER. H. W; JERVEY. M. T. \& VAIL. P. R. Eustatic controls on clastic deposition I - Conceptual framework. In: WILGUS, B.S; HASTINGS, C.G.ST.C; KENDALL, H.W; POSAMENTIER, C.A; ROSS, J.C.; VAN WAGONER (eds.). Sea Level Changes: An Integrated Approach. SEPM, Special Publication, p. 109-124, 1988.

RIDER, M. The Geological Interpretation of Well Logs. Sutherland: Rider-French Consulting Ltd, 280 p., 2000.

SCHLUMBERGER. Petrel geophysics course: Petrel 2011. Houston: Schlumberger information solutions, 469 p., 2011. 
SNEDDEN, J. W. \& BERGMAN, K. M. Isolated shallow marine sand bodies: deposits for all interpretations. SEPM Special Publication, v. 64, p. 1-11, 1999

SNEDDEN, J. W; TILLMAN, R. W. \& CULVER, S. J. Genesis and evolution of a mid-shelf, storm-built sand ridge, New Jersey continental shelf, USA. J. Sediment. Res, v. 81, p. 534552, 2011.

SPEARING, D. R. Upper Cretaceous Shannon Sandstonee: na offshore shallow marine sand body. In: ANNUAL WYOMING GEOLOGICAL ASSOCIATION FIELD CONFERENCE, 28, Casper, 1976. Resumos Expandidos...Wyoming: Wyoming Geological Association Guidebook, p. 65-72, 1976.

STRIDE, A. H; BELDERSON, R. H; KENYON, N. H. \& JOHNSON, M. A. Offshore tidal deposits: sand sheet and sand bank facies. In: STRIDE, A.H (ed.). Offshore Tidal Sands: Processes and Deposits. Chapman \& Hall, p. 95-125, 1982.

TILLMAN, R. W.; SWIFT, D.J.P.; WALKER, R. G. Shelf sands and sandstones. SEPM (Society for Sedimentary Geology) Short Course Notes, v. 13, p. 1-242, 1985.

VAIL, P.R. Seismic stratigraphy interpretation using sequence stratigraphy. Part I: Seismic stratigraphy interpretation procedure. In: BALLY, A. W (ed.). Atlas of Seismic Stratigraphy. American Association of Petroleum Geologists, p. $1-10,1987$
VEEKEN, P. C. H. Seismic Stratigraphy, Basin Analysis and Reservoir Characterization. London: Elsevier, 509 p., 2007.

ZHANG, X; DING, L; DU, J; LIU, D. \& LIU, H. Sedimentary characteristics and controlling factors of shelf sand ridges in the Pearl River Mouth Basin, northeast of South China Sea. Journal of Natural Gas Geoscience, v. 20, p. 1-15, 2017.

ZHUO. H; WANG. Y; SHI, H; ZHU, M; HE. M; CHEN, W. \& LI. H. Seismic geomorphology, architecture and genesis of Miocene shelf sand ridges in the Pearl River Mouth Basin, northern South China Sea. Marine and Petroleum Geology, v. 54, p. 106-122, 2014.
Submetido em 18 de junho de 2019 Aceito em 4 de fevereiro de 2020 